Article

\title{
Climate-Related Distribution Shifts of Migratory Songbirds and Sciurids in the White Mountain National Forest
}

\author{
Aimee Van Tatenhove ${ }^{1, * \mathbb{D}}$, Emily Filiberti ${ }^{1}$, T. Scott Sillett $^{1}{ }^{\mathbb{D}}$, Nicholas Rodenhouse $^{2}$ and \\ Michael Hallworth ${ }^{1}$ (D) \\ 1 Migratory Bird Center, Smithsonian Conservation Biology Institute, Washington, DC 20008, USA; \\ efiliberti@une.edu (E.F.); silletts@si.edu (T.S.S.); mhallworth@gmail.com (M.H.) \\ 2 Department of Biological Sciences, Wellesley College, 106 Central Street, Wellesley, MA 02481, USA; \\ nrodenho@wellesley.edu \\ * Correspondence: aimee.van.tatenhove@aggiemail.usu.edu; Tel.: +1-715-529-0159
}

Received: 31 December 2018; Accepted: 21 January 2019; Published: 23 January 2019

\begin{abstract}
Climate change has been linked to distribution shifts and population declines of numerous animal and plant species, particularly in montane ecosystems. The majority of studies suggest both that low-elevation avian and small mammal species are shifting up in elevation and that high-elevation avian communities are either shifting further upslope or relocating completely with an increase in average local temperatures. However, recent research suggests numerous high elevation montane species are either not shifting or are shifting down in elevation despite the local increasing temperature trends, perhaps as a result of the increased precipitation at high elevations. In this study, we examine common vertebrate species distributions across the Hubbard Brook valley in the White Mountain National Forest, including resident and migratory songbirds and small mammals, in relation to historic spring temperature and precipitation. We found no directional change in distributions through time for any of the species. However, we show that the majority of low-elevation bird species in our study area respond to warm spring temperatures by shifting upslope. All bird species that shifted were long-distance migrants. Each low-elevation migrant species responded differently to warm spring temperatures, through upslope distribution expansion, downslope distribution contraction, or total distribution shift upslope. In contrast, we found a majority of high-elevation bird species and both high- and low-elevation mammal species did not shift in response to spring temperature or precipitation and may be subject to more complex climate trends. The heterogeneous response to climate change highlights the need for more comprehensive studies on the subject and careful consideration for appropriate species and habitat management plans in northeastern montane regions.
\end{abstract}

Keywords: climate change; temperature; precipitation; Hubbard Brook; elevational shifts; mountains

\section{Introduction}

Mounting evidence suggests plants and animals are responding to ongoing climate change in numerous ways, including through significant distributional shifts [1-3]. A simple paradigm asserts that species will respond to rising temperatures by shifting their distributions poleward (e.g., References [4-6]) or up in elevation [2,3,7]. However, as time goes on, studies are finding some species are either not shifting or are shifting downslope through time, even as temperatures increase [8-11]. Yet, it is not clear what is driving montane species to shift heterogeneously and how montane species are ultimately moving in the face of climate change. 
Montane species can be particularly susceptible to the effects of climate change, because their distributions are elevationally constrained, leaving them vulnerable to range restriction or local extirpation through an inability to react sufficiently to a changing climate [12-14]. Montane songbird species and some small mammal species often occupy narrow niches $[15,16]$ and therefore may be sensitive to climate induced habitat alteration $[17,18]$. The elevational gradient of montane regions may also exacerbate the severity of climate change, as climate regimes are not changing uniformly at all elevations [19-21]. Most notably, precipitation rates are typically greater at high elevations, and precipitation is expected to increase more rapidly at high elevations with ongoing climate change [19-21]. As a result, precipitation may affect high-elevation species disproportionately [10,21], and in some cases, species may shift down to find areas with more favorable precipitation [12,21]. Temperature may also increase more rapidly at some higher elevation sites [20,22], putting further stress on montane communities. Migratory bird species may be particularly impacted, as individuals must recolonize areas yearly and may therefore shift greater distances than non-migratory species [23]. Songbirds and small mammals in northeastern montane forests may be especially vulnerable, as these regions are highly threatened by climate change $[19,20]$. However, with few studies of climate induced distributional shifts in northeastern forests, it is relatively unknown how climate change will impact songbird and small mammal species in these regions.

Long-term studies of songbird and small mammal communities are crucial to understanding how these communities are responding to a changing climate. The songbird and small mammal communities have been systematically surveyed annually since 1999 at the Hubbard Brook Experimental Forest (HBEF) within the White Mountain National Forest. Here, we used these long-term survey data to test whether changing climate has affected songbird and small mammal distributions in northeastern hardwood and boreal forests. We hypothesized that both temperature and precipitation contribute to fine scale distributional shifts within the songbird and small mammal communities and that songbird migratory status would affect the magnitude of the distribution shifts. If songbird and small mammal distributions are governed by climate, we predicted low-elevation species would shift upslope with warm temperatures, while high-elevation species would predominantly shift downslope in response to increased high-elevation precipitations. Additionally, we predicted that migratory songbird species that recolonize breeding grounds within HBEF yearly would exhibit larger distribution shifts than resident species.

\section{Materials and Methods}

\subsection{Study Site}

Hubbard Brook Experimental Forest $\left(43^{\circ} 56^{\prime} \mathrm{N}, 71^{\circ} 45^{\prime} \mathrm{W}, \mathrm{NH}, \mathrm{USA}\right.$; HBEF) is a 3600 ha watershed located within the White Mountain National Forest, ranging from 200-1000 m above sea-level (Figure 1). HBEF is forested and comprised of northern hardwoods found predominantly at low to middle elevations, transitioning to boreal spruce-fir forests at elevations above $800 \mathrm{~m} \mathrm{[24].} \mathrm{The} \mathrm{climate} \mathrm{within}$ HBEF is temperate, with long, cold winters and mild, wet summers [25]. Over 100 bird species regularly breed within HBEF, the majority of which are Neotropical migrants that spend temperate winters in the tropics. Eastern chipmunks (Tamias striatus Linnaeus; EACH) and red squirrels (Tamiasciurus hudsonicus Erxleben; RESQ) are also common in the valley and are frequent nest predators of these bird species $[26,27]$. 


\section{Hubbard Brook Experimental Forest}

WMNF, North Woodstock, NH

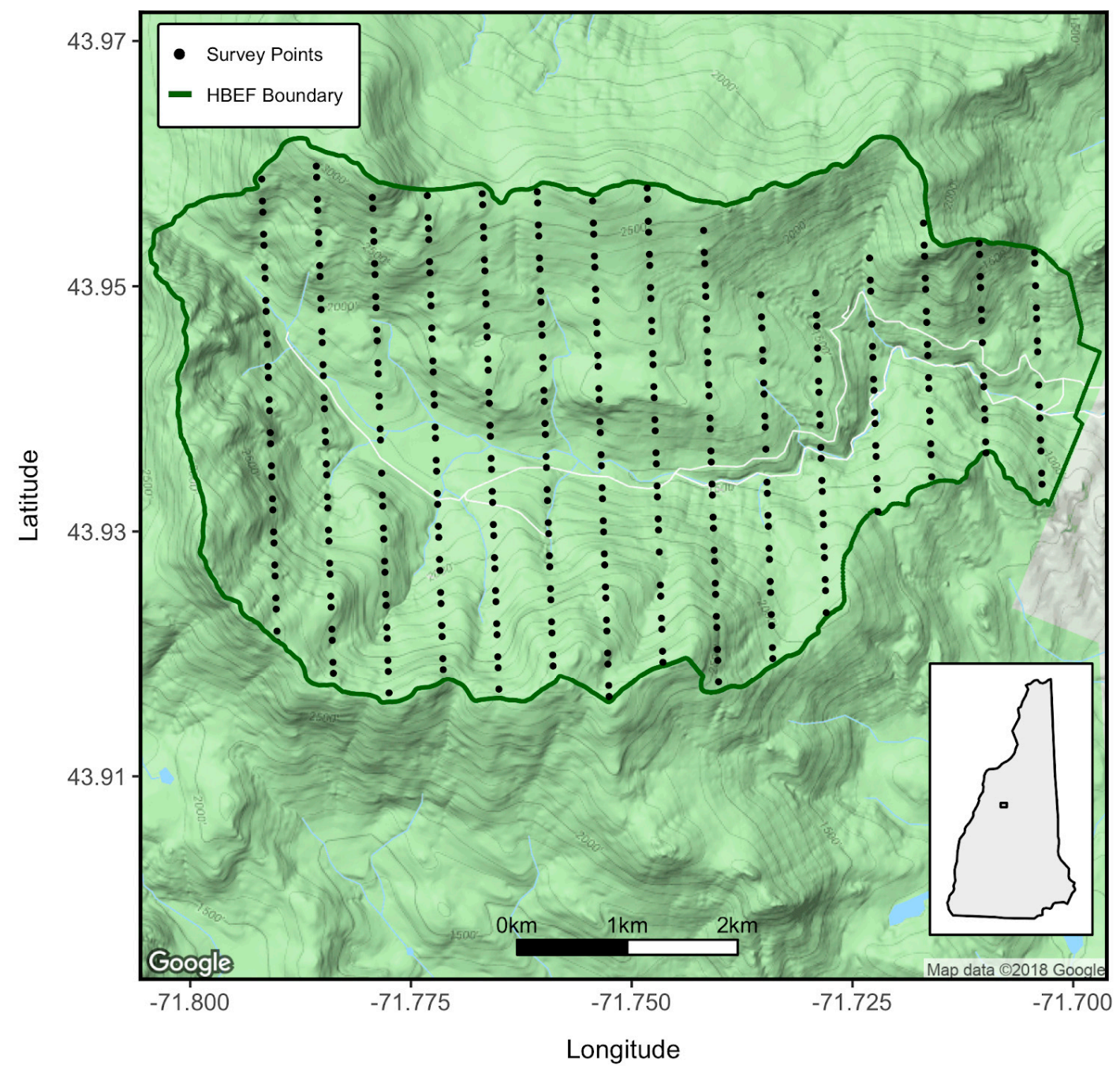

Figure 1. Map of Hubbard Brook Experimental Forest (HBEF) with survey locations in relation to New Hampshire.

\subsection{Survey Methods}

Point count surveys were used to collect avian and mammal occupancy data and were conducted annually from 1999 to 2016, excluding 2003 and 2004. Counts were conducted along 15 north-south transects, separated by $500 \mathrm{~m}$ that span the elevation gradient within HBEF. Survey locations along each transect were spaced either 100 or $200 \mathrm{~m}$ apart. Each survey location $(n=373)$ was surveyed at least three times during the breeding season (May through July), by a different trained surveyor each time. Point counts were conducted between 0530 and 1000 EDT (Eastern Daylight Time). Counts were not conducted in conditions that could hinder the surveyors' ability to detect individuals (rain, high winds, canopy drip, fog, etc.). During the ten-minute survey, all bird species, EACH, and RESQ seen or heard within $50 \mathrm{~m}$ of the point were recorded. Birds and mammals assessed to be outside $50 \mathrm{~m}$ were not used in this study to avoid accidental double counting of individuals at adjacent points.

\subsection{Surveyed Species}

We selected five songbird species to represent low-elevation bird species and five songbird species to represent high-elevation bird species, based on our prior knowledge of their breeding distributions 
within HBEF and to remain consistent with species selected in other regional studies [12,13]. Species designations were then confirmed using species occupancy curves over the elevation gradient in our study site, as outlined in the statistical methods. The low-elevation species we selected were the black-capped chickadee (Poecile atricapillus Linnaeus; $\mathrm{BCCH}$ ), black-throated blue warbler (Setophaga caerulescens Gmelin; BTBW), hermit thrush (Catharus guttatus Pallas; HETH), ovenbird (Seiurus aurocapilla Linnaeus; OVEN), and red-eyed vireo (Vireo olivaceus Linnaeus; REVI). The high-elevation species we selected were the blackpoll warbler (Setophaga striata Forster; BLPW), magnolia warbler (Setophaga magnolia Wilson; MAWA), dark-eyed junco (Junco hyemalis Linnaeus; DEJU), Swainson's thrush (Catharus ustulatus Nuttall; SWTH), and winter wren (Troglodytes hiemalis Viellot; WIWR).

Red squirrel (RESQ) data were available for all years, excluding the two years during which surveys were not conducted, 2003 and 2004. The eastern chipmunk (EACH) data was missing one additional year of data (2002). No other mammals were surveyed systematically during our study period. We categorized mammal species into low- and high-elevations using the same criteria we used for birds. EACH were designated as a low-elevation species and RESQ as a high-elevation species because of their association with conifers [16].

\subsection{Environmental Variables}

For this study, we focused on climate variables with long-term datasets available through our study period (1999-2016). We were primarily interested in how temperature and precipitation during the months when surveys were conducted affected species distributions within HBEF. Most migratory species arrive back at HBEF to breed in May. Therefore, we used mean May temperature and precipitation as potential drivers of distribution shifts since they coincide with the arrival of migratory bird species [28] and when RESQ and EACH pups first typically become active [29,30] (hereafter called "spring temperature" and "spring precipitation", unless specified). For migratory bird species that arrive at the breeding grounds in late May, and as such may not be influenced by early May weather, we chose to test whether mean June temperature and precipitation influenced their distribution shifts. Daily temperature and precipitation data from 1999 to 2014 were downloaded from the Long Term Ecological Research Network website (https: / / portal.lternet.edu). Additional temperature data for 2015 and 2016 were provided by the US Forest Service. All temperature and precipitation data were collected from the weather station at the USDA Forest Service Headquarters building at HBEF ( $252 \mathrm{~m}$ above sea level). Daily mean temperature and precipitation were averaged each year over May and June to generate mean annual May and June temperature and precipitation values.

\subsection{Statistical Methods}

Imperfect detection during animal surveys can lead to biased occupancy and abundance estimates and is common in point count data [31]. To account for imperfect species detection in our analyses, we used single and multi-season occupancy models (unmarked package v0.12-0, [32]) to predict true species occupancy in relation to elevation. Using these adjusted occupancy estimates, we confirmed our a priori songbird and small mammal elevation designations by assessing how their multiyear site occupancy probability varied over the elevation gradient within HBEF (Figure 2). Species occupancy curves that increased to $100 \%$ predicted the occupancy above $800 \mathrm{~m}$ (approximately where the ecotone between deciduous and boreal forests reside in HBEF) were confirmed as high-elevation species, and species with a predicted occupancy that peaked and then declined before $800 \mathrm{~m}$ in elevation were confirmed as low-elevation species. 


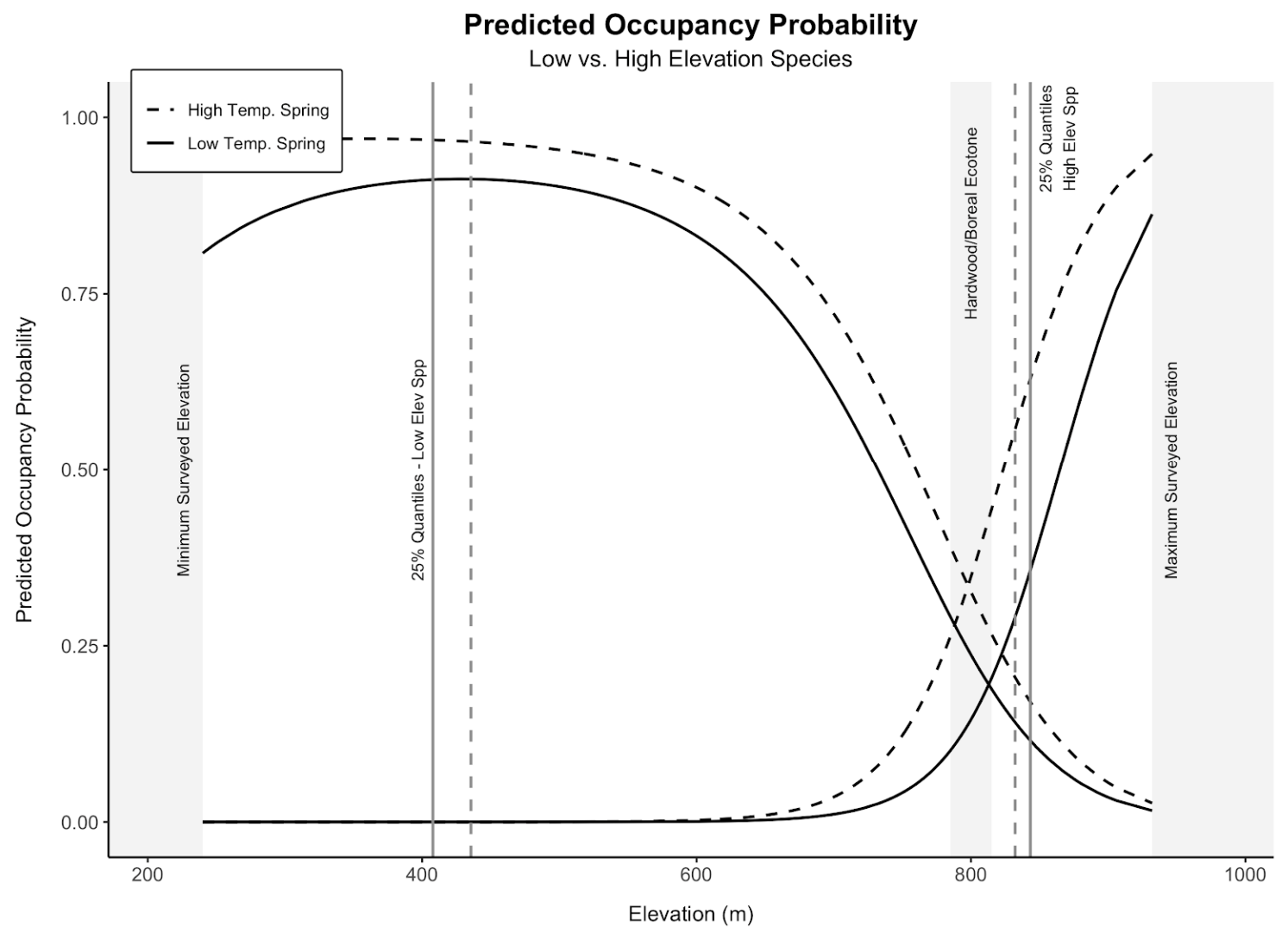

Figure 2. The simulated occupancy probabilities of high- and low-elevation species occupying a given elevation within HBEF, New Hampshire in relation to varying mean spring temperatures based on survey data corrected for imperfect detection. The solid lines represent species occupancy in a year with low spring temperatures, and the dashed lines represent occupancy in a year with high spring temperatures. The quantiles show how species distribution changes within their yearly range with mean spring temperatures.

The elevational gradient within HBEF (approximately 200 to $1000 \mathrm{~m}$ ) likely does not encompass the full elevational distribution of some of the species included in our analyses, particularly those of high-elevation species. Following DeLuca and King [12], we accounted for partial elevational distributions by segmenting the predicted occupancy for each species into quantiles $(2.5 \%, 5 \%, 25 \%$, $50 \%, 75 \%, 95 \%$, and $97.5 \%$ ) to allow us to assess how species distributions were shifting and whether species distributions shifted uniformly, contracted, or expanded. Separate linear models for each predicted occupancy quantile were used to assess whether elevational distributions shifted through time within our study period. Linear models for each quantile were then used to assess whether the observed elevational distribution shifts were in response to average annual spring temperatures or average annual spring precipitations. We used Akaike's Information Criterion for limited sample sizes (AICc, MuMIn package v1.42.1, [33]) to identify the most parsimonious models among our candidate set of models. For low-elevation bird species, we examined the relationship between environmental covariates and the elevation of the $97.5 \%$ quantile across all low-elevation species, as the upper distributional range appears more sensitive to changes in climate [2,21]. For high-elevation bird species, we focused on the $2.5 \%$ quantile across all high-elevation species because HBEF is at the lower elevation band of their distribution. For our mammal species, we tested model appropriateness at the $50 \%$ quantile across both mammal species because our mammals include both high-elevation and low-elevation species.

All data are presented as mean $\pm 95 \%$ confidence interval, and results were considered significant at $p<0.05$. All data were analyzed in $\mathrm{R}$ (v3.5.1, [34]). 


\section{Results}

\subsection{Environmental Variables}

Historic mean annual temperature $\left(\mathrm{df}=59, R^{2}=0.36, p<0.001\right.$; Figure 3$)$ and precipitation rates $\left(\mathrm{df}=35, R^{2}=0.09, p=0.044\right.$; Figure 3) have increased within HBEF, mirroring the trends observed in the northeastern North America over the past 100 years $[19,20]$. However, there was no change in the mean May temperature $\left(\mathrm{df}=16, R^{2}=0.06, p=0.165\right)$ or precipitation $\left(\mathrm{df}=14, R^{2}=-0.07, p=0.909\right)$ over the 18-year period (1999 to 2016) that coincides with our survey data. The same 18-year period had substantial annual variability in both temperature and precipitation (Figure 3).

\section{Temperature and Precipitation Trends in HBEF}

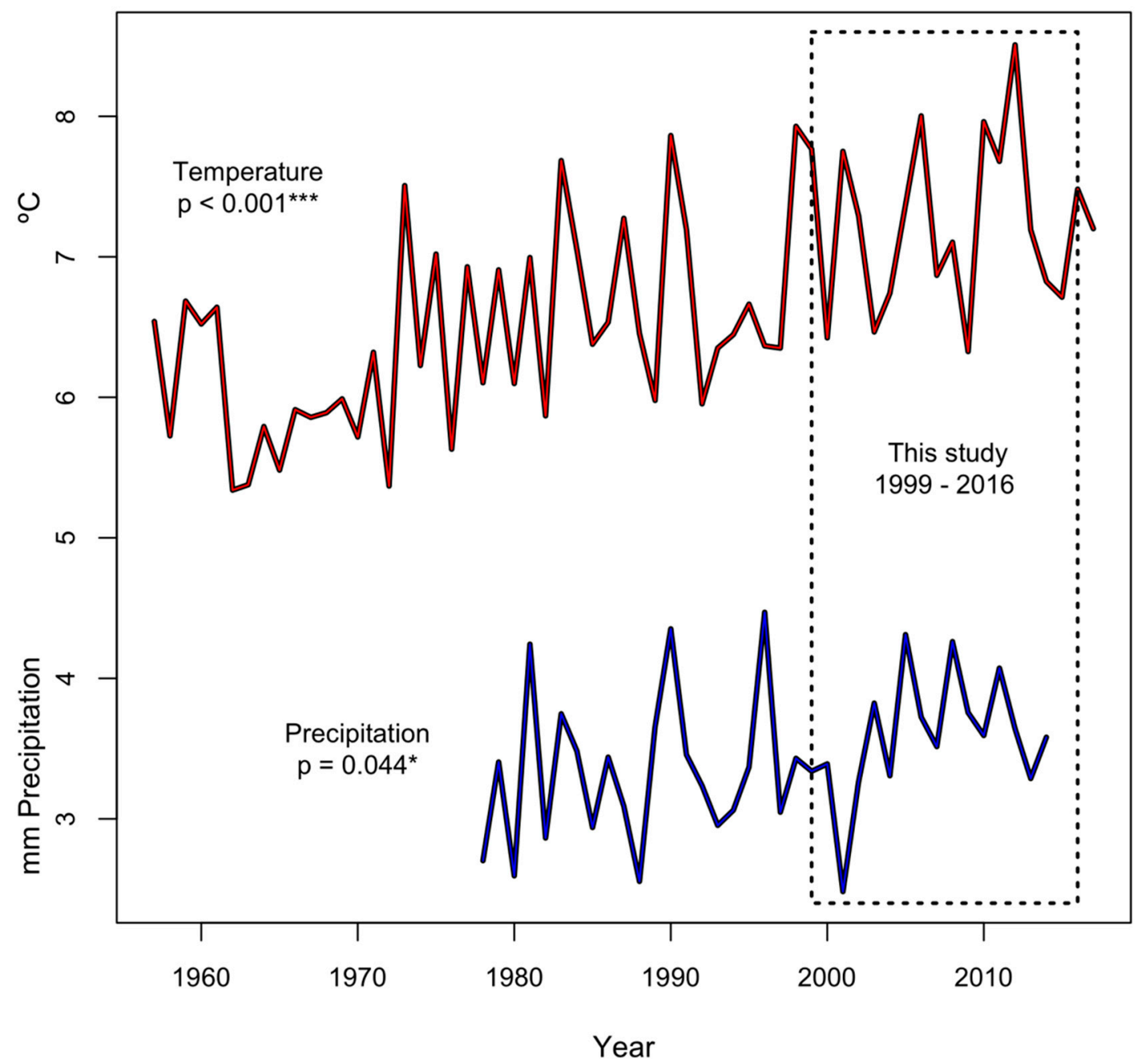

Figure 3. The mean annual temperature (1957-2017) and precipitation (1978-2014) trends in HBEF, New Hampshire. All data were collected from the USDA Forest Service Headquarters building at HBEF at $252 \mathrm{~m}$ above sea level.

\subsection{Low-Elevation Birds}

We found no evidence that low-elevation songbird species distributions shifted significantly with time over the study period (Table S1). However, three of five low-elevation bird species shifted upslope significantly with warm spring temperatures (BTBW, OVEN, and REVI; Table 1 and Table S2), while no-low elevation species shifted as a result of mean spring precipitation (Table S3). BTBWs contracted the bottom half of their distribution upslope by an average of $9.11 \mathrm{~m} /{ }^{\circ} \mathrm{C}$, 
while their upper distribution above $50 \%$ remained stable. In contrast to BTBWs, OVENs expanded their upper distribution (95 to $97.5 \%$ quantiles) upslope by an average of $10.58 \mathrm{~m} /{ }^{\circ} \mathrm{C}$, while their lower distribution remained stable. REVIs shifted nearly their entire elevational distribution ( $5 \%$ to $97.5 \%$ predicted occupancy quantiles) upslope significantly with warm spring temperature, moving the top $50 \%$ of their distribution upslope an average of $16.94 \mathrm{~m} /{ }^{\circ} \mathrm{C}$, with the top $5 \%$ shifting an average of $20.48 \mathrm{~m} /{ }^{\circ} \mathrm{C}$. All $(100 \%)$ of the species that shifted significantly were species that migrate to wintering grounds outside of the United States [35-37] (hereafter "long-distance migrants"), while the remaining two species were residents or migrants within the United States [38,39] (hereafter "short-distance migrants").

The mean spring temperature alone was the most parsimonious of our candidate models for low-elevation bird species (Table S4), although two other models (temperature + precipitation and time + temperature) had $\triangle \mathrm{AICc}$ values of $<2.0$.

Table 1. HBEF songbird and small mammal species distribution shifts in relation to the mean spring temperature. The mean May temperature was used for all species, excluding BLPW, where the mean June temperature was used. Asterisks $\left(^{*}\right)$ denote statistically significant $p$-values $\left({ }^{*} p \leq 0.05 ;{ }^{* *} p \leq 0.01\right.$; $\left.{ }^{* * *} p<0.001\right)$. Periods (.) denote near significant $p$-values $(0.05<p \leq 0.10)$. Abbreviations: Black-capped chickadee (BCCH), black-throated blue warbler (BTBW), hermit thrush (HETH), ovenbird (OVEN), red-eyed vireo (REVI), blackpoll warbler (BLPW), magnolia warbler (MAWA), dark-eyed junco (DEJU), Swainson's thrush (SWTH), winter wren (WIWR), red squirrel (RESQ), and eastern chipmunk (EACH).

\begin{tabular}{|c|c|c|c|c|c|}
\hline \multicolumn{6}{|c|}{ Mean Spring Temperature (1999-2016) } \\
\hline \multicolumn{6}{|c|}{ Low-Elevation Species } \\
\hline Spp. & $\%$ Occu & Intercept & $R^{2}$ & $p$ & Significance \\
\hline \multirow{7}{*}{ BTBW } & $2.5 \%$ & 8.71 & 0.30 & 0.016 & * \\
\hline & $5 \%$ & 10.29 & 0.38 & 0.007 & ** \\
\hline & $25 \%$ & 10.40 & 0.61 & 0.000 & $* * *$ \\
\hline & $50 \%$ & 7.06 & 0.38 & 0.007 & $* *$ \\
\hline & $75 \%$ & 3.77 & -0.01 & 0.370 & \\
\hline & $95 \%$ & 3.43 & -0.04 & 0.545 & \\
\hline & $97.5 \%$ & 4.39 & -0.03 & 0.446 & \\
\hline \multirow{7}{*}{ OVEN } & $2.5 \%$ & -0.90 & -0.01 & 0.390 & \\
\hline & $5 \%$ & -1.00 & -0.04 & 0.534 & \\
\hline & $25 \%$ & 0.40 & -0.07 & 0.882 & \\
\hline & $50 \%$ & 2.78 & -0.01 & 0.361 & \\
\hline & $75 \%$ & 5.78 & 0.10 & 0.129 & \\
\hline & $95 \%$ & 10.12 & 0.22 & 0.040 & * \\
\hline & $97.5 \%$ & 11.05 & 0.21 & 0.041 & * \\
\hline \multirow{7}{*}{ REVI } & $2.5 \%$ & 0.77 & 0.14 & 0.082 & . \\
\hline & $5 \%$ & 1.62 & 0.21 & 0.040 & $*$ \\
\hline & $25 \%$ & 6.43 & 0.53 & 0.001 & $* * *$ \\
\hline & $50 \%$ & 10.95 & 0.67 & 0.000 & $* * *$ \\
\hline & $75 \%$ & 15.86 & 0.70 & 0.000 & $* * *$ \\
\hline & $95 \%$ & 21.55 & 0.55 & 0.001 & $* * *$ \\
\hline & $97.5 \%$ & 19.41 & 0.42 & 0.004 & $* *$ \\
\hline \multicolumn{6}{|c|}{ High-Elevation Species } \\
\hline \multirow{7}{*}{ BLPW } & $2.5 \%$ & 14.81 & -0.06 & 0.656 & \\
\hline & $5 \%$ & 9.47 & -0.01 & 0.392 & \\
\hline & $25 \%$ & 4.93 & 0.21 & 0.041 & * \\
\hline & $50 \%$ & 3.47 & 0.34 & 0.011 & * \\
\hline & $75 \%$ & 1.83 & 0.33 & 0.012 & * \\
\hline & $95 \%$ & 0.42 & 0.47 & 0.002 & $* *$ \\
\hline & $97.5 \%$ & 0.16 & 0.23 & 0.034 & * \\
\hline
\end{tabular}




\subsection{High-Elevation Birds}

We found that most high-elevation songbird species distributions did not shift significantly with time. Two species shifted portions of their distributions upslope with time (SWTH and DEJU) but only for one predicted occupancy quantile for each (25\% and 75\% respectively; Table S1). One of three high-elevation, long-distance migrant species [40] shifted distributions with the mean spring temperature (BLPW; Table 1), while the remaining long-distance migrants [41,42] and resident species $[43,44]$ did not (Table S2). Contrary to our predictions, no high-elevation species shifted downslope, with the exception of the BLPW. The upper edge of the BLPW's distribution, at the maximum elevation of our study site, contracted slightly downslope with warm May temperature (97.5\% quantile; $\left.-0.14 \mathrm{~m} /{ }^{\circ} \mathrm{C}\right)$. However, BLPW distribution from the $25 \%$ to $97.5 \%$ quantiles expanded upslope with the mean June temperature (Table 1), with an average upslope shift of $2.16 \mathrm{~m} /{ }^{\circ} \mathrm{C}$.

No high-elevation bird distributions shifted as a result of the mean spring precipitation (Table S3). Our most parsimonious model of our candidate high-elevation species models was spring precipitation (Table S4), although models for both temperature and time had $\triangle \mathrm{AICc}$ values of $<2.0$.

\subsection{Mammals}

We found no evidence that time, mean spring temperature, or mean spring precipitation had any significant effect on RESQ or EACH distributions through our study period (Tables S1-S3). The mean spring temperature was the most parsimonious model of our candidate models for mammals (Table S4) but only slightly more so than precipitation $(\triangle \mathrm{AICc}=0.05)$ and time $(\triangle \mathrm{AICc}=0.11)$.

\section{Discussion}

Overall, we did not find that songbird or small mammal elevational distributions were shifting through time within our study period. This is perhaps because temperature and precipitation did not increase significantly over our study period. Instead, our study species responded proximately to annual variations in climatic variables, with the majority of low-elevation songbird species responding to warm spring temperatures by shifting upslope (Figure S1a). However, most high-elevation songbird species and both small mammal species did not respond to temperature or precipitation (Figure S1a,b), perhaps because shifts seen in other studies occurred at higher elevations than those within our study site and climate constraints may be more extreme at higher elevations [8,11,12].

The distributional shifts we observed in low-elevation songbirds may be related to migratory status. Avian migratory status has been assessed by a handful of other studies (e.g. References [21,23]) but is not commonly assessed by studies looking at distributional shifts. Walther et al. [23] argue that migratory species are more likely to shift than resident species because they recolonize areas yearly. Within HBEF, first time breeders often must colonize new territories and are therefore subject to distribution shifts through changes in abundance and reactions to climatic variables and territory quality. This is in contrast with the resident species that take the slower, more stable route of local population extinction and colonization. They therefore exhibit smaller and slower distribution shifts [23], and is perhaps why we did not see shifts in resident species. Similar to Walther's [23] findings, we found that all three of our low-elevation songbird species that shifted upslope with warm spring temperatures were long-distance migrants, while the two species that did not shift significantly were a resident species (BCCH) and a short-distance migrant (HETH). Notably, our low-elevation migrant with the longest migration route and latest spring arrival time of our low-elevation songbirds, the REVI, was our most responsive species to warm spring temperatures. REVIs shifted nearly their entire distribution upslope with warm spring temperatures and shifted upslope farther than any of our other low-elevation species, at almost $+20 \mathrm{~m}$ per degree of temperature increase. The other two low-elevation species that responded to warm spring temperature (BTBW and OVEN) responded to a lesser degree, shifting shorter distances and only portions of their distribution (Table 1). Long distance migrants have no way of assessing specific climate conditions at their summer breeding grounds, 
and they may instead use cues other than temperature, including day length $[45,46]$ and favorable flying conditions at wintering grounds [47] to determine when to begin spring migration. Plastic responses to habitat quality upon arrival at summer breeding grounds may help buffer against phenological mismatches inherent with having a relatively set migratory schedule. Species with the longest migration routes, such as the REVI, which winters in South America [37], may benefit from having plastic settlement patterns, and these long migration routes may be one of the underlying reasons we see REVIs shift more than other species.

Contrary to our predictions, low-elevation mammals did not shift significantly with time, temperature, or precipitation. Although $\mathrm{EACH}$ is a frequent nest predator of songbird eggs and nestlings [26,27], their diet consists primarily of tree seeds, including those from the exceptionally long-lived [48] American beech trees (Fagus grandifolia Ehrhart) and sugar maple trees (Acer saccharum Marshall) [29,49]. EACH are therefore highly reliant on seed producing tree species as a food source, especially for caching food for consumption over the winter months [29,49]. In non-mast years, when tree seeds are scarce, EACH still rely heavily on vegetative food sources [29]. This reliance on seed producing tree species and other vegetation may be driving distribution shifts, or the lack thereof, as EACH may be tracking the slower changes in distribution of long-lived tree species over changes in temperature and precipitation [50].

In contrast with low-elevation songbird species, we found no distributional shifts in high-elevation songbirds (Figure S1a), with the exception of the BLPW, which shifted downslope with warm May temperatures. However, with an average shift of $-0.14 \mathrm{~m} /{ }^{\circ} \mathrm{C}, \mathrm{BLPW}$ distributional shifts as a result of the mean May temperature were much smaller than those seen in low-elevation species. Others have also documented high-elevation birds shifting downslope $[8,12,21]$, although the proposed causes vary. Some potential explanations include shifting vegetation $[8,12]$ and increased high-elevation precipitation [12,21]. Neither of these explanations appear to be occurring within HBEF, as HBEF forest structure appears stable [51] and BLPWs did not respond to the mean spring precipitation. However, BLPW distributional shifts may be responding to the mean June temperature. Contrary to shifts related to the May temperatures, BLPWs showed a significant upslope expansion through all but the lowest reaches of their distribution with warm June temperatures (Figure S1a). BLPWs are long-distance migrants [40] and are typically the latest birds to arrive in HBEF out of the species we assessed in this study. They typically arrive to HBEF near the end of May and begin nesting shortly after [40]. As a result, they are likely influenced most by the temperature at the end of May, which, within HBEF, are more typical of temperatures we would expect to see in June. So, why is the BLPW shifting while other high-elevation species are not? Like the REVI, BLPWs are one of the longest distance migrants of our high-elevation species [40] and may be more plastic in their response to environment as a way to buffer against phenological mismatches when arriving at breeding grounds.

Overall, the lack of observed distribution shifts by high-elevation songbird and mammal species at HBEF, with the exception of BLPWs, may be due in part to the elevation range in our study site. Most of our high-elevation sites are lower than those in numerous other studies that observed birds and small mammals move downslope (elevational maximums: this study, 903 m; Archaux [8], 3099 m; DeLuca and King [12], 1470 m; etc.), and climate constraints on our high-elevation species may not be as extreme as those at higher elevation sites $[19,20]$. Boreal habitats within HBEF are found primarily above $800 \mathrm{~m}$ in elevation and are therefore restricted to the highest ridges in the valley. As a result, we also may be missing reactions to precipitation by high-elevation species due to the small elevational range of boreal spruce-fir within HBEF. Alternately, high-elevation species in HBEF may be experiencing the effects of increased precipitation but may not be shifting significantly out of necessity for specific breeding habitats. Archaux [8] found that avian abundance and distribution within two study sites in the French Alps was closely tied with habitat distribution shifts, despite significant warming. Similar studies of high-elevation mammals like RESQ have found they may also be tracking habitat distribution shifts over changes in climatic conditions, much like their low-elevation counterparts [11,50]. RESQ are heavily reliant on conifer seeds as a food source and typically hold 
territories in or near stands of conifers [16,52]. Elevationally restricted habitat may cause increased competition by habitat-constrained species for breeding or food caching territory $[12,15,29]$, and as a result, high-elevation species may be using all of the available habitat that suits their needs, regardless of quality. If this is the case, any evidence of habitat tracking would likely only be seen over longer time periods, as vegetation distribution shifts are typically slower than temperature change, due to the long lifespans of trees [1,20].

\subsection{Future Implications}

Distributional shifts will likely impact montane passerines and small mammals in several ways. With temperature and precipitation rates expected to increase faster at higher elevations, species shifting upslope may encounter novel combinations of climate and vegetation. Also, because some species are shifting while others are not, the avian community composition will likely change as a result, and novel species interactions may arise [53]. As birds shift in elevation, they are also likely to encounter non-avian species and habitats they have not interacted with before [53,54]. While these novel interactions may be beneficial for some species, it is unknown how this will ultimately affect sensitive populations and ecosystem dynamics. For instance, nest predation is a major factor in avian reproductive success or failure $[27,49,55]$, and as bird species distributions shift, birds moving into areas where RESQ and EACH overlap may encounter higher rates of nest predation, potentially impacting their ability to produce young. Additionally, species that are not shifting may encounter southern and lower-elevation species that are expanding into areas left by species moving upslope or poleward [6,13], like red-bellied woodpeckers (Melanerpes carolinus), tufted titmice (Baeolophus bicolor), and eastern gray squirrels (Sciurus carolinensis). Species with contracting distributions, like the BTBW, may also face increased intraspecies competition during the breeding season, as the preferred breeding habitat decreases.

Small yearly distributional shifts may not be ecologically significant alone, and over short timescales, the impacts of elevational shifts may not be obvious. However, as temperatures increase over the long term, these small shifts may lead to larger scale shifts that will affect ecosystems and individual species alike. The mean annual temperature in New England is expected to increase 1.7 to $4.4{ }^{\circ} \mathrm{C}$ or more by the year $2100[19,20]$, and under the worst-case warming scenario, we could see REVI and other highly plastic species shift upslope an average of almost $100 \mathrm{~m}$ by the year 2100 . For species occupying sites near the maximum elevation within HBEF, an upslope shift of $100 \mathrm{~m}$ will likely extirpate them from the valley entirely. Precipitation and temperature increases are expected to be more severe at higher elevations $[20,21]$. As a result, species at higher elevations in the region may shift even farther than the species detailed here [12,21,54], thus exacerbating the effects of elevational shifts and novel community interactions.

\subsection{Further Research}

Long-term datasets are invaluable for measuring species distribution shifts. Therefore, the continued collection of species occupancy and abundance coupled with climate variables is essential to understanding the impacts of climate change on montane species as well as impacts on lower elevation species that may eventually colonize montane habitats. It is likely other local and regional variables in addition to temperature and precipitation influence elevational distribution shifts in our study species. Other variables should be assessed to increase our understanding of how species distributions are changing, including vegetation shifts at transition zones, changes in winter snowpack depth, intra and interspecies interactions, and prey distribution shifts.

HBEF supports a wide variety of avian species, including high-elevation species, despite HBEF being at the lower end of many of their elevational distributions. Yet, as climate continues to change and species continue to shift upslope, we may begin to lose high-elevation species within HBEF as they move to higher elevation sites elsewhere. Mountaintop extirpation as a result of climate change 
has been the focus of only a few studies in the northeast and should be explored further to increase our understanding of how species distributions shift with climate change.

\section{Conclusions}

We found almost no directional change in distributions through time for any of our songbird or small mammal species. However, we found three of our five $(60 \%)$ low-elevation bird species (BTBW, OVEN, and REVI) responded to warm spring temperatures by shifting upslope. All low-elevation songbird species that shifted were long-distance migrants, while those that did not shift were year-round residents of HBEF or short-distance migrants (BCCH and $\mathrm{HETH}$, respectively). Each low-elevation migrant species responded differently to warm spring temperatures, through upslope distribution expansion, downslope distribution contraction, or total distribution shift upslope. BLPW was the only high-elevation songbird species that shifted with warm spring temperature (downslope with the mean May temperature and upslope with the mean June temperature). The remaining high-elevation bird species (MAWA, DEJU, SWTH, and WIWR) and both high- and low-elevation mammal species (RESQ and EACH, respectively) did not shift in response to spring temperature or precipitation. This may be due to the limited elevation range in our study site, which may not experience the severe climate constraints found at higher elevations.

Supplementary Materials: The following are available online at http:/ /www.mdpi.com/1999-4907/10/2/84/s1, Figure S1: Elevational Shifts in Target Species, Table S1: Hubbard Brook Experimental Forest (HBEF) songbird and small mammal species distribution shifts in relation to time in years, Table S2: HBEF songbird and small mammal species distribution shifts in relation to the mean spring temperature, Table S3: HBEF songbird and small mammal species distribution shifts in relation to the mean spring precipitation.

Author Contributions: Conceptualization, A.V.T., E.F., and M.H.; methodology, A.V.T., E.F., and M.H.; software, A.V.T. and M.H.; validation, M.H.; formal analysis, A.V.T. and M.H.; investigation, N.R. and T.S.S.; resources, N.R. and T.S.S.; data curation, M.H.; writing-original draft preparation, A.V.T. and M.H.; writing-review and editing, M.H., E.F., T.S.S. and N.R.; visualization, A.V.T.; supervision, M.H.; project administration, N.R., T.S.S. and M.H.; funding acquisition, N.R. and T.S.S.

Funding: This manuscript is a contribution of the Hubbard Brook Ecosystem Study. Hubbard Brook is part of the Long-Term Ecological Research (LTER) network, which is supported by the U.S. National Science Foundation. The Hubbard Brook Experimental Forest is operated and maintained by the USDA Forest Service, Northern Research Station, Newtown Square, PA. This research was funded by the National Science Foundation, grant numbers 9810221 and 0423259.

Acknowledgments: A special thanks to Amey Bailey at the USDA Forest Service headquarters at HBEF for compiling missing years of temperature data on our behalf. We also thank our two anonymous reviewers whose helpful suggestions strengthened our manuscript considerably, Bill DeLuca for the helpful statistics suggestions, and all of the dedicated field technicians who collected data for our avian and mammal dataset.

Conflicts of Interest: The authors declare no conflict of interest.

\section{References}

1. Beckage, B.; Osborne, B.; Gavin, D.G.; Pucko, C.; Siccama, T.; Perkins, T. A rapid upward shift of a forest ecotone during 40 years of warming in the Green Mountains of Vermont. Proc. Natl. Acad. Sci. USA 2008, 105, 4197-4202. [CrossRef] [PubMed]

2. Freeman, B.G.; Class Freeman, A.M. Rapid upslope shifts in New Guinean birds illustrate strong distributional responses of tropical montane species to global warming. Proc. Natl. Acad. Sci. USA 2014, 111, 4490-4494. [CrossRef] [PubMed]

3. Zuckerberg, B.; Woods, A.M.; Porter, W.F. Poleward shifts in breeding bird distributions in New York State. Glob. Chang. Biol. 2009, 15, 1866-1883. [CrossRef]

4. Hitch, A.T.; Leberg, P.L. Breeding Distributions of North American Bird Species Moving North as a Result of Climate Change. Conserv. Biol. 2007, 21, 534-539. [CrossRef] [PubMed]

5. La Sorte, F.A.; Thompson, F.R. Poleward shifts in winter ranges of North American birds. Ecology 2007, 88, 1803-1812. [CrossRef] [PubMed] 
6. Myers, P.; Lundrigan, B.L.; Hoffman, S.M.G.; Haraminac, A.P.; Seto, S.H. Climate-induced changes in the small mammal communities of the Northern Great Lakes Region. Glob. Chang. Biol. 2009, 15, 1434-1454. [CrossRef]

7. Chen, I.-C.; Shiu, H.-J.; Benedick, S.; Holloway, J.D.; Chey, V.K.; Barlow, H.S.; Hill, J.K.; Thomas, C.D. Elevation increases in moth assemblages over 42 years on a tropical mountain. Proc. Natl. Acad. Sci. USA 2009, 106, 1479-1483. [CrossRef]

8. Archaux, F. Breeding upwards when climate is becoming warmer: No bird response in the French Alps. IBIS 2004, 146, 138-144. [CrossRef]

9. Lenoir, J.; Gegout, J.-C.; Guisan, A.; Vittoz, P.; Wohlgemuth, T.; Zimmermann, N.E.; Dullinger, S.; Pauli, H.; Willner, W.; Svenning, J.-C. Going against the flow: Potential mechanisms for unexpected downslope range shifts in a warming climate. Ecography 2010, 33, 295-303. [CrossRef]

10. McCain, C.M.; Colwell, R.K. Assessing the threat to montane biodiversity from discordant shifts in temperature and precipitation in a changing climate: Climate change risk for montane vertebrates. Ecol. Lett. 2011, 14, 1236-1245. [CrossRef]

11. Wen, Z.; Wu, Y.; Ge, D.; Cheng, J.; Chang, Y.; Yang, Z.; Xia, L.; Yang, Q. Heterogeneous distributional responses to climate warming: Evidence from rodents along a subtropical elevational gradient. BMC Ecol. 2017, 17, 17. [CrossRef] [PubMed]

12. DeLuca, W.V.; King, D.I. Montane birds shift downslope despite recent warming in the northern Appalachian Mountains. J. Ornithol. 2017, 158, 493-505. [CrossRef]

13. Rodenhouse, N.L.; Matthews, S.N.; McFarland, K.P.; Lambert, J.D.; Iverson, L.R.; Prasad, A.; Sillett, T.S.; Holmes, R.T. Potential effects of climate change on birds of the Northeast. Mitig. Adapt. Strategies Glob. Chang. 2008, 13, 517-540. [CrossRef]

14. Sekercioglu, C.H.; Schneider, S.H.; Fay, J.P.; Loarie, S.R. Climate Change, Elevational Range Shifts, and Bird Extinctions: Elevation, Climate Change, and Bird Extinctions. Conserv. Biol. 2008, 22, 140-150. [CrossRef] [PubMed]

15. Sabo, S.R.; Holmes, R.T. Foraging Niches and the Structure of Forest Bird Communities in Contrasting Montane Habitats. Condor 1983, 85, 121-138. [CrossRef]

16. Saunders, D.A. Adirondack Mammals; College of Environmental Science and Forestry, State University of New York: New York, NY, USA, 1988; 216p.

17. Crick, H.Q.P. The impact of climate change on birds: Impact of climate change on birds. IBIS 2004, 146, 48-56. [CrossRef]

18. Jetz, W.; Wilcove, D.S.; Dobson, A.P. Projected Impacts of Climate and Land-Use Change on the Global Diversity of Birds. PLoS Biol. 2007, 5, e157. [CrossRef]

19. IPCC Climate Change 2014: Synthesis Report. In Contribution of Working Groups I, II and III to the Fifth Assessment Report of the Intergovernmental Panel on Climate Change; Core Writing Team; Pachauri, R.K.; Meyer, L.A. (Eds.) IPCC: Geneva, Switzerland, 2014; p. 151.

20. Janowiak, M.K.; D'Amato, A.W.; Swanston, C.W.; Iverson, L.; Thompson, F.R.; Dijak, W.D.; Matthews, S.; Peters, M.P.; Prasad, A.; Fraser, J.S.; et al. New England and Northern New York Forest Ecosystem Vulnerability Assessment and Synthesis: A Report from the New England Climate Change Response Framework Project; U.S. Department of Agriculture, Forest Service, Northern Research Station: Newtown Square, PA, USA, 2018.

21. Tingley, M.W.; Koo, M.S.; Moritz, C.; Rush, A.C.; Beissinger, S.R. The push and pull of climate change causes heterogeneous shifts in avian elevational ranges. Glob. Chang. Biol. 2012, 18, 3279-3290. [CrossRef]

22. Seidel, T.M.; Weihrauch, D.M.; Kimball, K.D.; Pszenny, A.A.P.; Soboleski, R.; Crete, E.; Murray, G. Evidence of Climate Change Declines with Elevation Based on Temperature and Snow Records from 1930s to 2006 on Mount Washington, New Hampshire, U.S.A. Arct. Antarct. Alpine Res. 2009, 41, 362-372. [CrossRef]

23. Walther, G.-R.; Post, E.; Convey, P.; Menzel, A.; Parmesan, C.; Beebee, T.J.C.; Fromentin, J.-M.; Hoegh-Guldberg, O.; Bairlein, F. Ecological responses to recent climate change. Nature 2002, 416, 389-395. [CrossRef]

24. Hubbard Brook Research Foundation. Chapter 01: The Hubbard Brook Ecosystem Study: Site, History, and Research Approaches; HBEF: North Woodstock, NH, USA, 2018. Available online: https:/ /hubbardbrook.org/ online-book (accessed on 31 December 2018). 
25. Holmes, R.T.; Sherry, T.W.; Sturges, F.W. Bird Community Dynamics in a Temperate Deciduous Forest: Long-Term Trends at Hubbard Brook. Ecol. Monogr. 1986, 56, 201-220. [CrossRef]

26. Reitsma, L.R.; Holmes, R.T.; Sherry, T.W. Effects of Removal of Red Squirrels, Tamiasciurus hudsonicus, and Eastern Chipmunks, Tamias striatus, on Nest Predation in a Northern Hardwood Forest: An Artificial Nest Experiment. Oikos 1990, 57, 375. [CrossRef]

27. Sherry, T.W.; Wilson, S.; Hunter, S.; Holmes, R.T. Impacts of nest predators and weather on reproductive success and population limitation in a long-distance migratory songbird. J. Avian Biol. 2015, 46, 559-569. [CrossRef]

28. Rodewald, P. The Birds of North America; Cornell Laboratory of Ornithology: Ithaca, NY, USA, 2015.

29. Elliott, L. Social behavior and foraging ecology of the eastern chipmunk (Tamias striatus) in the Adirondack Mountains. Smithson. Contrib. Zool. 1978, 1-107. [CrossRef]

30. Rusch, D.A.; Reeder, W.G. Population Ecology of Alberta Red Squirrels. Ecology 1978, 59, 400-420. [CrossRef]

31. Chandler, R.B.; Royle, J.A.; King, D.I. Inference about density and temporary emigration in unmarked populations. Ecology 2011, 92, 1429-1435. [CrossRef]

32. Fiske, I.; Chandler, R. unmarked: An R Package for Fitting Hierarchical Models of Wildlife Occurrence and Abundance. J. Stat. Softw. 2011, 43, 1-23. [CrossRef]

33. Bartoń, K. MuMIn: Multi-Model Inference, R package Version 1.42.1; 2018. Available online: https:/ /CRAN.Rproject.org / package=MuMIn (accessed on 31 December 2018).

34. R Core Team R. A Language and Environment for Statistical Computing; R Foundation for Statistical Computing: Vienna, Austria, 2018.

35. Holmes, R.T.; Kaiser, S.A.; Rodenhouse, N.L.; Sillett, T.S.; Webster, M.S.; Pyle, P.; Patten, M.A. Black-Throated Blue Warbler (Setophaga caerulescens), version 3.0. In The Birds of North America; Rodewald, P.G., Ed.; Cornell Lab of Ornithology: Ithaca, NY, USA, 2017. [CrossRef]

36. Porneluzi, P.; Van Horn, M.A.; Donovan, T.M. Ovenbird (Seiurus aurocapilla), version 2.0. In The Birds of North America; Poole, A.F., Ed.; Cornell Lab of Ornithology: Ithaca, NY, USA, 2011. [CrossRef]

37. Cimprich, D.A.; Moore, F.R.; Guilfoyle, M.P. Red-eyed/Chivi Vireo (Vireo olivaceus/chivi), version 2.0. In The Birds of North America; Poole, A.F., Gill, F.B., Eds.; Cornell Lab of Ornithology: Ithaca, NY, USA, 2000. [CrossRef]

38. Dellinger, R.; Wood, P.B.; Jones, P.W.; Donovan, T.M. Hermit Thrush (Catharus guttatus), version 2.0. In The Birds of North America; Poole, A.F., Ed.; Cornell Lab of Ornithology: Ithaca, NY, USA, 2012. [CrossRef]

39. Foote, J.R.; Mennill, D.J.; Ratcliffe, L.M.; Smith, S.M. Black-capped Chickadee (Poecile atricapillus), version 2.0. In The Birds of North America; Poole, A.F., Ed.; Cornell Lab of Ornithology: Ithaca, NY, USA, 2010. [CrossRef]

40. DeLuca, W.; Holberton, R.; Hunt, P.D.; Eliason, B.C. Blackpoll Warbler (Dendroica striata). In The Birds of North America; Poole, A.F., Ed.; Cornell Lab of Ornithology: Ithaca, NY, USA, 2013. [CrossRef]

41. Mack, D.E.; Yong, W. Swainson's Thrush (Catharus ustulatus), version 2.0. In The Birds of North America; Poole, A.F., Gill, F.B., Eds.; Cornell Lab of Ornithology: Ithaca, NY, USA, 2000. [CrossRef]

42. Dunn, E.H.; Hall, G.A. Magnolia Warbler (Setophaga magnolia), version 2.0. In The Birds of North America; Poole, A.F., Ed.; Cornell Lab of Ornithology: Ithaca, NY, USA, 2010. [CrossRef]

43. Nolan, V., Jr.; Ketterson, E.D.; Cristol, D.A.; Rogers, C.M.; Clotfelter, E.D.; Titus, R.C.; Schoech, S.J.; Snajdr, E. Dark-eyed Junco (Junco hyemalis), version 2.0. In The Birds of North America; Poole, A.F., Gill, F.B., Eds.; Cornell Lab of Ornithology: Ithaca, NY, USA, 2002. [CrossRef]

44. Hejl, S.J.; Holmes, J.A.; Kroodsma, D.E. Winter Wren (Troglodytes hiemalis), version 2.0. In The Birds of North America; Poole, A.F., Gill, F.B., Eds.; Cornell Lab of Ornithology: Ithaca, NY, USA, 2002. [CrossRef]

45. Wolfson, A. Day Length, Migration, and Breeding Cycles in Birds. Sci. Mon. 1952, 74, 191-200.

46. Bauer, S.; Nolet, B.A.; Giske, J.; Chapman, J.W.; Åkesson, S.; Hedenström, A.; Fryxell, J.M. Cues and decision rules in animal migration. In Animal Migration; Milner-Gulland, E.J., Fryxell, J.M., Sinclair, A.R.E., Eds.; Oxford University Press: Oxford, UK, 2011; pp. 68-87, ISBN 978-0-19-956899-4.

47. Richardson, W.J. Timing and Amount of Bird Migration in Relation to Weather: A Review. Oikos 1978, 30, 224. [CrossRef]

48. Loehle, C. Tree life history strategies: The role of defenses. Can. J. For. Res. 1988, 18, 209-222. [CrossRef]

49. Clotfelter, E.D.; Pedersen, A.B.; Cranford, J.A.; Ram, N.; Snajdr, E.A.; Nolan, V.; Ketterson, E.D. Acorn mast drives long-term dynamics of rodent and songbird populations. Oecologia 2007, 154, 493-503. [CrossRef] [PubMed] 
50. Ulateig, G. Vegetation Changes and Small Rodent Responses along Alpine Gradients in Oceanic and Continental Climate; Norwegian University of Life Sciences: Ås, Norway, 2010.

51. van Doorn, N.S.; Battles, J.J.; Fahey, T.J.; Siccama, T.G.; Schwarz, P.A. Links between biomass and tree demography in a northern hardwood forest: A decade of stability and change in Hubbard Brook Valley, New Hampshire. Can. J. For. Res. 2011, 41, 1369-1379. [CrossRef]

52. Smith, M.C. Red Squirrel Responses to Spruce Cone Failure in Interior Alaska. J. Wildl. Manag. 1968, 32, 305-317. [CrossRef]

53. Blois, J.L.; Zarnetske, P.L.; Fitzpatrick, M.C.; Finnegan, S. Climate Change and the Past, Present, and Future of Biotic Interactions. Science 2013, 341, 499-504. [CrossRef] [PubMed]

54. Moritz, C.; Patton, J.L.; Conroy, C.J.; Parra, J.L.; White, G.C.; Beissinger, S.R. Impact of a Century of Climate Change on Small-Mammal Communities in Yosemite National Park, USA. Science 2008, 322, 261-264. [CrossRef] [PubMed]

55. Bradley, J.E.; Marzluff, J.M. Rodents as Nest Predators: Influences on Predatory Behavior and Consequences to Nesting Birds. Auk 2003, 120, 1180-1187. [CrossRef]

(C) 2019 by the authors. Licensee MDPI, Basel, Switzerland. This article is an open access article distributed under the terms and conditions of the Creative Commons Attribution (CC BY) license (http://creativecommons.org/licenses/by/4.0/). 